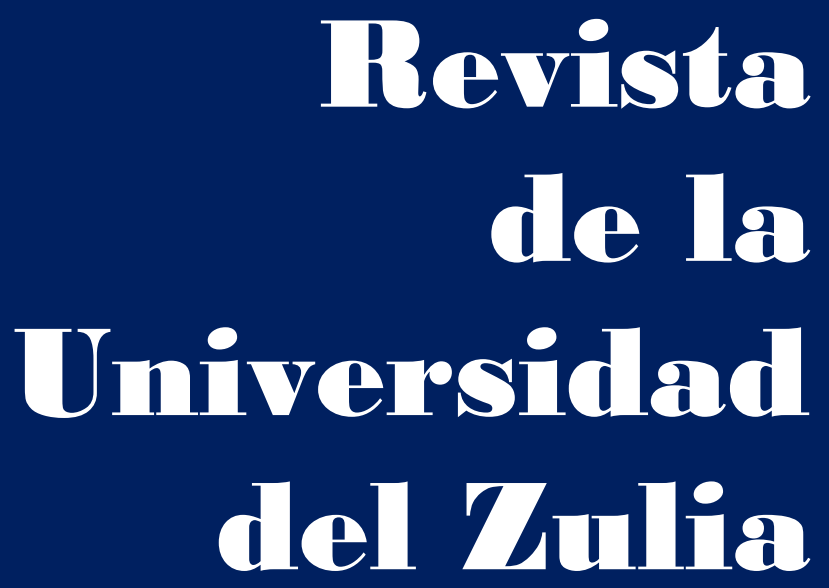

Fundada en 1947

por el Dr. Jesús Enrique Lossada

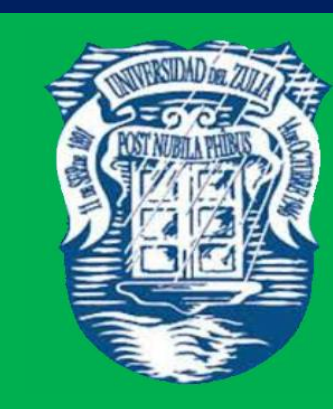

Ciencias del

Agrad,

Ingemiería

y Tecinología

\section{Aกัต 13 No $\mathbf{3 6}$} Enero - Abril 2022

Tercera Épaca

Maracailbo-Venezuela 
REVISTA DE LA UNIVERSIDAD DEL ZULIA. $3^{a}$ época. Año $13 \mathrm{~N}^{\circ}$ 36, 2022

Dolores Betún Beltrán et al. /// Efecto de un recubrimiento a base de quitosano y extracto de cebolla ... 70-79 DOI: http://dx.doi.org/10.46925//rdluz.36.05

\title{
Efecto de un recubrimiento a base de quitosano y extracto de cebolla sobre la vida útil y las características sensoriales de filetes de dorado en refrigeración
}

\author{
Dolores Betún Beltrán * \\ Gustavo Elías Martínez Valenzuela ** \\ Génesis Nathaly Cantillo Holguín ***
}

RESUMEN

Los productos pesqueros son altamente susceptibles al deterioro por diversas causas; el crecimiento bacteriano es el principal factor que limita su vida útil. La presente investigación evaluó el efecto de un recubrimiento a base de quitosano y extracto de cebolla sobre la vida útil y características sensoriales de filetes de dorado. El recubrimiento de mayor aceptación sensorial fue T6 elaborado con 3\% de quitosano y $1 \%$ de extracto de cebolla, el cual obtuvo valores por debajo de los rangos permisibles en la norma legal vigente hasta los 21 días en refrigeración (29,12 mg N/100 g). El análisis microbiológico evidenció ausencia de aerobios mesófilos hasta el séptimo día de almacenamiento en refrigeración, incrementando gradualmente su conteo hasta los 21 días $\left(1,9 \mathrm{xl}^{3} \mathrm{UFC} / \mathrm{g}\right)$, cumpliendo con lo establecido en la normativa legal vigente ( $\left.1 \times 10^{5} \mathrm{UFC} / \mathrm{g}\right)$; de igual manera se comprobó la ausencia de Coliformes totales y E. coli durante el tiempo establecido.

PALABRAS CLAVE: alimento; industria alimentaria; agroindustria; tecnología alimentaria.

*Tesista. Universidad Agraria del Ecuador. ORCID: https://orcid.org/0000-0002-2094-9489. ** Docente - Investigador. Universidad Agraria del Ecuador. ORCID: https://orcid.org/00000002-0424-1632. E-mail: gmartinez@uagraria.edu.ec

*** Tesista. Universidad Agraria del Ecuador. ORCID: https://orcid.org/0000-0002-2995$\underline{6212 .}$

El artículo contiene los aportes del trabajo de titulación presentado como requisito para la obtención del título de Ingeniero Agrícola Mención Agroindustrial, en la Universidad Agraria del Ecuador. 


\section{Effect of a coating based on chitosan and onion extract on useful life and sensory characteristics of Mahi-Mahi fillets in cooling}

Fishing products are highly susceptible to deterioration due to various causes, bacterial growth is the main factor that limits their useful life. The present investigation evaluated the effect of a coating based on chitosan and onion extract on the useful life and sensory characteristics of Mahi-Mahi fillets. The coating with the highest sensory acceptance was T6 made with 3\% chitosan and 1\% onion extract, which obtained values below the permissible ranges in the current legal standard up to 21 days in refrigeration $(29.12 \mathrm{mg} \mathrm{N} / 100 \mathrm{~g})$. The microbiological analysis showed the absence of mesophilic aerobes until the seventh day of storage in refrigeration, gradually increasing their count until 21 days (1.9x103 CFU / g), complying with the provisions of current legal regulations (lx105 CFU / g), likewise, the absence of total coliforms and E. coli was verified during the established time.

KEYWORDS: Food; Food industry; Agroindustry; Food technology

\section{Introducción}

Los productos pesqueros son altamente susceptibles al deterioro por lo que se encuentran dentro de los alimentos perecederos; si bien pueden alterarse por diversas causas, el crecimiento bacteriano es el principal factor que limita su vida útil (Condori, 2014).

Después de la captura y muerte del pescado, éste sufre inmediatamente un deterioro, debido que la velocidad de degradación es más elevada que la de otros tipos de carnes; este proceso de degradación es llevado a cabo en una primera etapa, por enzimas propias del músculo del pescado y posteriormente por enzimas producidas por los microrganismos que ingresan al músculo (Oliveira, Dragonetti y Friss, 2001).

La industria alimentaria demanda tecnologías emergentes para aumentar la vida útil del pescado y ofrecer productos seguros y de calidad; por esta razón la aplicación de recubrimientos o películas en filetes de dorado representa una alternativa útil para su conservación, pues gracias a las propiedades que estas presentan, como: barrera de gases, vapor de agua, agentes antimicrobianos y antioxidantes naturales, permiten incrementar la calidad, seguridad y estabilidad del producto pesquero. Es decir, crea una barrera entre el producto y la atmósfera que lo rodea, de esta manera, se protege al alimento evitando la 


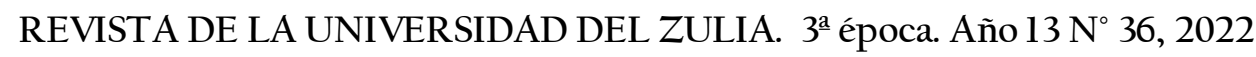

Dolores Betún Beltrán et al. /// Efecto de un recubrimiento a base de quitosano y extracto de cebolla ... 70-79 DOI: http://dx.doi.org/10.46925//rdluz.36.05

pérdida de humedad, reducción de la oxidación de las grasas, controlar el pardeamiento y verificar la calidad y propiedades del producto final (García, 2014).

Las películas y recubrimientos comestibles protegen de los daños físicos causados por impacto mecánico, presión, vibraciones entre otros. Las películas deben ser resistentes a la rotura y abrasión y además deben ser flexibles para adaptarse al alimento. Además, pueden incorporarse ingredientes funcionales como: antioxidantes, antimicrobianos, saborizantes o colorantes que ayuden a evitar la posible deformación del alimento a recubrir (Cadena, 2018).

El interés comercial del quitosano, se debe a las características biológicas favorables que posee, incluyendo la biodegradabilidad, biocompatibilidad y no toxicidad, propiedades que le otorgan un uso fundamental en las industrias farmacéuticas, biomédicas y alimentarias (Valenzuela y Arias, 2012). El objetivo de la presente investigación fue evaluar el efecto de un recubrimiento a base de quitosano y extracto de cebolla sobre la vida útil y las características sensoriales de filetes de dorado en refrigeración

\section{Materiales y métodos}

\section{1.l. Materia prima}

El pescado dorado con escam a fue adquirido en el mercado "La Caraguay" en la ciudad de Guayaquil, el cual cuenta con un pequeño muelle donde llegan embarcaciones artesanales con la pesca del día. El pescado fresco fue colocado rápidamente dentro de un cooler, cubierta con capas de hielo, para mantener una temperatura menor a $4{ }^{\circ} \mathrm{C}$ con el fin de evitar la degradación prematura. La norma NTE INEN 1896 (2013: 3) señala que: "El olor, color y sabor deben ser los característicos del producto. No se permiten olores y sabores objetables persistentes e inconfundibles que sean signo de descomposición".

Una vez retirado las escamas, se realizó el eviscerado mediante un corte ventral con un cuchillo hasta la abertura anal, con la finalidad de permitir el fácil acceso a la cavidad abdominal para retirar completamente las vísceras, luego de lo cual se realizó un lavado con el fin de eliminar restos de vísceras, escamas y sangre. Una vez limpio el pescado se procedió a realizar los filetes de aproximadamente $1 \mathrm{~cm}$ de espesor, formando filetes homogéneos de aproximadamente $12 \times 4 \mathrm{~cm}$.

1.2. Procedimiento del extracto de cebolla 


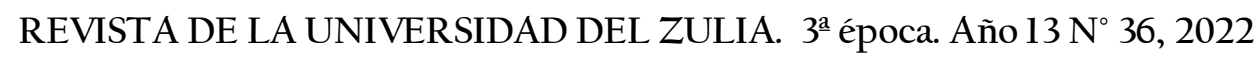

Dolores Betún Beltrán et al. /// Efecto de un recubrimiento a base de quitosano y extracto de cebolla ... 70-79

DOI: http://dx.doi.org/10.46925//rdluz.36.05

Se realizó un corte en ambos extremos de las cebollas y retira la capa exterior. Posterior se añadió los pedazos en el extractor durante 5 minutos. Una vez cernido y obtenido el extracto, se colocó en un recipiente plástico de cierre hermético.

1.3. Proceso de elaboración del recubrimiento a base de quitosano y extracto de cebolla

Se preparó 1 litro de solución de quitosano 1 \% p/v en ácido acético 1 \% v/v., luego se colocó en una placa de calentamiento $\left(40{ }^{\circ} \mathrm{C} / 450 \mathrm{rpm}\right)$ durante 24 horas. Una vez solubilizado la solución se incorporó $10 \mathrm{ml}$ de glicerol y el extracto de cebolla agitando por 2 horas.

\subsection{Aplicación del recubrimiento}

El recubrimiento se aplicó en $1 \mathrm{~kg}$ de filetes de dorado mediante el método de inmersión y se dejó reposar por 5 minutos. Luego de la aplicación del recubrimiento, se colocó en mallas los filetes para eliminar el exceso del mismo. Los filetes estuvieron expuestos a temperatura de refrigeración $4 \pm 1^{\circ} \mathrm{C}$.

En este trabajo se evaluaron dos factores de estudio: el Factor A correspondió a las concentraciones de quitosano (l y 3\%), y el Factor B las concentraciones de extracto de cebolla $(0 ; 0,5$ y $1 \%)$.

\subsection{Características sensoriales}

Se escogió un panel sensorial de 30 jueces semi-entrenados para el análisis de color, olor, sabor y textura de las muestras de cada uno de los tratamientos en estudio, para lo cual se utilizó una escala hedónica de 5 puntos, donde 1 equivale a muy malo y 5 significa muy bueno.

Para realizar la prueba sensorial se sometieron los filetes a cocción en una plancha caliente por 2 minutos aproximadamente, sin agregar ningún condimento para evitar que interfiera en los resultados de la prueba. Las muestras fueron servidas a cada juez identificando cada uno con números aleatorios

El tratamiento que tuvo mayor aceptación sensorial por parte del panel de jueces fue analizado a los 7,14 y 21 días conservado en refrigeración $\left(<4^{\circ} \mathrm{C}\right)$

\subsection{Contenido de bases nitrogenadas}




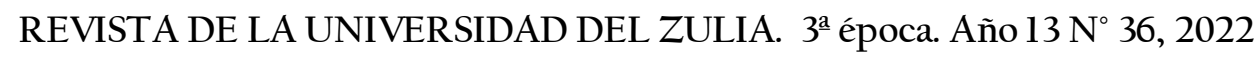

Dolores Betún Beltrán et al. /// Efecto de un recubrimiento a base de quitosano y extracto de cebolla ... 70-79

DOI: http://dx.doi.org/10.46925//rdluz.36.05

La norma NTE INEN 1896.2013 menciona que el contenido de bases nitrogenadas volátiles totales (NVBT) no debe superar $30 \mathrm{mg}$ N/100 g muestra.

La concentración de NVBT se calculó en base al procedimiento establecido en la norma NTE INEN 182. Se pesa de 5 a 10 g de la muestra preparada y se transfiere cuantitativamente al balón de destilación. Se agrega sobre la muestra $300 \mathrm{~cm} 3$ de agua destilada, 1 a 2 g de óxido de magnesio y unas gotas de alcohol octílitico para evitar la formación de espuma. Se conecta inmediatamente el balón al condensador y se destila por 25 minutos. El extremo de salida del condensador debe estar sumergido en $50 \mathrm{~cm} 3$ de la solución valorada de ácido sulfúrico 0,1 N contenido en el Erlenmeyer de $250 \mathrm{~cm} 3$, a la cual se debe agregar unas gotas del indicador rojo de metilo. Una vez terminada la destilación, comprobada con papel indicador, se procede a titular el exceso de ácido contenido en el matraz Erlenmeyer con la solución de hidróxido de sodio 0,1 N. Se debe realizar un ensayo en blanco con todos los reactivos siguiendo el mismo procedimiento anteriormente descrito. La valoración del destilado recogido, mediante la siguiente ecuación:

mg N/100 gramos de muestra $=\quad\left(\mathrm{V}_{\mathrm{m}}-\mathrm{V}_{\mathrm{b}}\right) * 0.14 * 2 * 100$

$\mathrm{m}$

\subsection{Vida útil}

El análisis microbiológico, se realizó a la muestra de mayor aceptación en laboratorios externos de acuerdo a los requerimientos establecidos en la Norma INEN 1896: 2013. Los criterios microbiológicos analizados fueron: Recuento de microorganismos mesófilos (ufc/g), mediante el método de ensayo estipulado en la AOAC 990.12; Coliformes totales y E. coli (ufc/g) utilizando el procedimiento establecido en la AOAC 998.08

\subsection{Análisis estadístico}

El diseño de investigación empleado fue un diseño en bloques al azar con arreglo factorial ( $2 \times 3$ ). Los datos proporcionados por los jueces quienes conformaron la fuente de bloqueo fueron sometidos a un análisis de varianza (ANOVA) con el fin de establecer diferencias significativas entre los tratamientos para cada variable: color, olor, sabor y textura. Para la comparación de medias se utilizó la prueba de Tukey al 5\% de error tipo 1 ( $p<0,05)$, para lo cual se empleó el software Infostat.

\section{Resultados y discusión}


REVISTA DE LA UNIVERSIDAD DEL ZULIA. $3^{a}$ época. Año $13 \mathrm{~N}^{\circ}$ 36, 2022

Dolores Betún Beltrán et al. /// Efecto de un recubrimiento a base de quitosano y extracto de cebolla ... 70-79

DOI: http://dx.doi.org/10.46925//rdluz.36.05

La tabla 1 muestra los resultados del análisis sensorial efectuado en los filetes de pescado dorado con el recubrimiento a base de quitosano y extracto de cebolla. El tratamiento de mayor aceptación sensorial fue el Tratamiento 6, con la combinación de a 2: quitosano 3\% y b3: extracto de cebolla 1\%., el mismo que fue el mejor calificado en cada uno de los atributos sensoriales.

Tabla 1. Promedios de análisis sensorial

\begin{tabular}{|c|c|c|c|c|c|c|}
\hline № & Factor A & Factor B & Color & Olor & Sabor & Textura \\
\hline 1 & al: Quitosano 1 \% & $\begin{array}{c}\text { bl: extracto de cebolla } 0 \\
\%\end{array}$ & $4.3 \mathrm{ab}$ & $4.4 \mathrm{a}$ & $4.3 \mathrm{a}$ & $4.1 \mathrm{~b}$ \\
\hline 2 & al: Quitosano 1 \% & $\begin{array}{l}\text { b2: extracto de cebolla } \\
\qquad .5 \%\end{array}$ & $4.5 \mathrm{a}$ & $4.4 \mathrm{a}$ & $4.3 \mathrm{a}$ & $4.1 \mathrm{ab}$ \\
\hline 3 & al: Quitosano 1 \% & $\begin{array}{c}\text { b3: extracto de cebolla } 1 \\
\qquad \%\end{array}$ & $4.6 \mathrm{a}$ & $4,3 \mathrm{a}$ & $4.3 \mathrm{a}$ & $4.4 \mathrm{ab}$ \\
\hline 4 & a2: Quitosano $3 \%$ & $\begin{array}{c}\text { bl: extracto de cebolla } 0 \\
\%\end{array}$ & $4.3 \mathrm{ab}$ & $4.4 \mathrm{a}$ & $4.4 \mathrm{a}$ & $4.6 \mathrm{a}$ \\
\hline 5 & a2: Quitosano $3 \%$ & $\begin{array}{c}\text { b2: extracto de cebolla } \\
0.5 \%\end{array}$ & $3.9 \mathrm{~b}$ & $3.8 \mathrm{~b}$ & $4.2 \mathrm{a}$ & $4.1 \mathrm{ab}$ \\
\hline 6 & a2: Quitosano $3 \%$ & $\begin{array}{c}\text { b3: extracto de cebolla l } \\
\qquad \%\end{array}$ & $4.4 \mathrm{a}$ & $4.5 \mathrm{a}$ & $4.5 \mathrm{a}$ & $4.6 \mathrm{ab}$ \\
\hline
\end{tabular}

Betún-Beltrán et al., 2021.

Se puede apreciar que los componentes del recubrimiento no transfieren color, olor o sabores atípicos al producto, debido a que no se observó diferencias significativas entre los distintos tratamientos aplicados, salvo pequeñas excepciones, estos resultados coinciden con los obtenidos por Montaño Cota (2016), quien estudió el efecto de un extracto etanólico obtenido a partir de la planta de tomate (Olanum lycopersicum) incorporado en un recubrimiento comestible a base de quitosano sobre la frescura, calidad y vida de anaquel del filete de sierra (Scomberomorus sierra) almacenado en hielo, donde se evidenció que no existieron diferencias significativas entre los tratamientos en estudio 


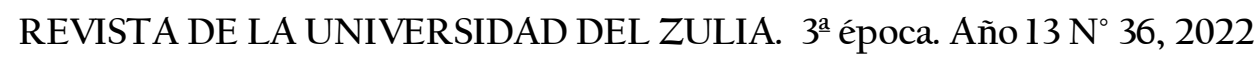

Dolores Betún Beltrán et al. /// Efecto de un recubrimiento a base de quitosano y extracto de cebolla ... 70-79

DOI: http://dx.doi.org/10.46925//rdluz.36.05

El contenido de bases nitrogenadas volátiles totales se realizó al tratamiento de mayor aceptación (T6: Quitosano 3\% y extracto de cebolla 1 \%). La tabla 2 muestra los miligramos de nitrógeno obtenidos por cada 100 gramos de producto durante el almacenamiento en refrigeración a los 7, 14 y 21 días.

Tabla 2. Contenido de bases nitrogenadas volátiles totales

\begin{tabular}{ccc}
\hline Días de refrigeración & $\begin{array}{c}\text { Volumen consumido en la } \\
\text { titulación }\end{array}$ & mgN/100g \\
\hline 7 & $4,2 \mathrm{ml}$ & 10,92 \\
14 & $6,9 \mathrm{ml}$ & 18,48 \\
21 & $10,7 \mathrm{ml}$ & 29,12
\end{tabular}

Betún-Beltrán et al., 2021.

El tratamiento 6: quitosano al $3 \%$ y extracto de cebolla al $1 \%$, obtuvo valores por debajo de los rangos permisibles según lo estipulado en la normativa legal vigente NTE INEN 182 (30 mg N/100 g) hasta los 21 días en refrigeración: 10.92 mg N/100 g (7 días), 18.48 mg N/100 g (14 días) y $29.12 \mathrm{mg} \mathrm{N} / 100$ g (2l días). Mero y Valencia (2018) evaluaron un recubrimiento comestible para filetes de tilapia roja (Oreochromis sp) a partir de almidón de yuca (Manihot esculenta crantz) y aceite esencial de romero (Tosmarinus officinalis), el análisis estadístico demostró, que la media del testigo es ligeramente mayor que la del filete con recubrimiento, el testigo presenta una mayor varianza, y al llegar al décimo día de almacenamiento alcanza un valor máximo de 33.83 mg N/100g similar al recubrimiento; por esta razón se asumió que no hay diferencia alguna entre los grupos sin recubrimiento y con recubrimiento a base de almidón de yuca y aceite esencial de romero. Por otra parte, Raeisi (2014) elaboró un recubrimiento a partir de carboximetil celulosa enriquecido con aceite esencial Zataria multiflora y extracto de la semilla de uva para filetes de trucha arcoíris; la muestra de control dio una concentración inicial de $12.67 \mathrm{mg} / 100 \mathrm{~g}$ de NBVT, mientras que las muestra sin recubrimiento tuvieron un valor de $11.34 \mathrm{mg} / 100 \mathrm{~g}$ de NBVT. Luego de un plazo de 20 días de almacenamiento lograron valores de $52.00 \mathrm{mg} / 100 \mathrm{~g}$ y $40.30 \mathrm{mg} / 100 \mathrm{~g}$. 


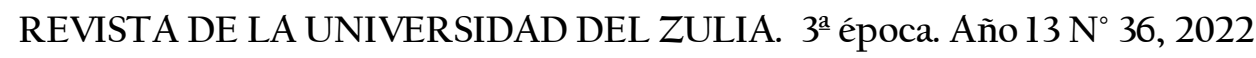

Dolores Betún Beltrán et al. /// Efecto de un recubrimiento a base de quitosano y extracto de cebolla ... 70-79

DOI: http://dx.doi.org/10.46925//rdluz.36.05

En la tabla 3 se muestran los resultados del análisis de vida útil, de aerobios mesófilos, coliformes totales y E. coli realizado al tratamiento de mayor aceptación sensorial, a los 7, 14 y 21 días de almacenamiento en refrigeración $\left(3 \pm 2{ }^{\circ} \mathrm{C}\right)$.

Tabla 3. Tiempo de vida útil

\begin{tabular}{lcccc}
\hline \multicolumn{1}{c}{ Parámetros } & $\begin{array}{r}\text { Tiempo } \\
\text { natural: } \\
7 \text { días }\end{array}$ & $\begin{array}{r}\text { Tiempo } \\
\text { natural: } \\
14 \text { días }\end{array}$ & $\begin{array}{r}\text { Tiempo } \\
\text { natural: } \\
21 \text { días }\end{array}$ & UNIDAD \\
\hline Aerobios Mesófilos & $<10$ & $8 \times 10^{2}$ & $1.9 \times 10^{3}$ & $\mathrm{UFC/g}$ \\
Coliformes Totales & $<10$ & $<10$ & $<10$ & $\mathrm{UFC/g}$ \\
E. coli & $<10$ & $<10$ & $<10$ & $\mathrm{UFC} / \mathrm{g}$
\end{tabular}

Betún-Beltrán et al., 2021.

Los resultados del análisis de vida útil evidenciaron que hasta el séptimo día de almacenamiento se mantuvieron ausentes ( $<10 \mathrm{UFC} / \mathrm{g})$, luego se observó un incremento a los 14 y 21 días de almacenamiento en refrigeración de 8 x $10^{2}$ y 1.9 x $10^{3} \mathrm{UFC} / \mathrm{g}$ respectivamente; dichos valores están dentro de los rangos establecidos en la normativa legal vigente ( 1 x $10^{5}$ $\mathrm{UFC} / \mathrm{g}$ ), por lo tanto, se demuestra la eficacia del recubrimiento aplicado. Al respecto, Suárez y Martínez (2018) mencionan que el quitosano, aunque es una sustancia antimicrobiana natural, tiene una limitación en la difusión en un medio de agar, de modo que solamente los microorganismos en contacto directo con los sitios activos de quitosano son inhibidos y podría ser necesaria la adición de otro antimicrobiano, dicha función se le otorgó al extracto de cebolla. Cabe resaltar que estas películas antimicrobianas, son más efectivas frente a las bacterias Gram-positivas que frente a las bacterias Gram-negativas (Otero, 2019).

Por su parte, Mero y Valencia (2018) evidenciaron que la media de ambos grupos (grupo 1: sin recubrimiento y grupo 2: con recubrimiento de almidón de yuca y aceite esencial de romero) presentan una diferencia mínima, teniendo una varianza casi idéntica, pero se recurrió a la prueba paramétrica, con la que se obtuvo un resultado del 31.73\%, cumpliendo con la hipótesis nula, es decir que no existe diferencia alguna entre ambos grupos. Sin embargo, en un estudio realizado Song (2011) con un recubrimiento a partir de alguinato y antioxidantes aplicados a filetes de brema (Megalobrama amblycephala), la cantidad de aerobios 


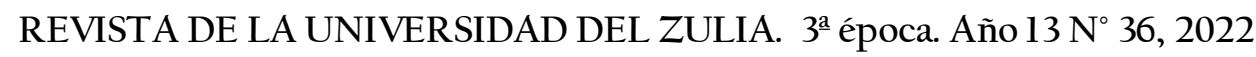

Dolores Betún Beltrán et al. /// Efecto de un recubrimiento a base de quitosano y extracto de cebolla ... 70-79 DOI: http://dx.doi.org/10.46925//rdluz.36.05

total para todas las muestras empezó en $3 \log _{10} \mathrm{UFC/g}$, pero después de un periodo de 18 días de almacenamiento la muestra con recubrimiento logró un valor de $5.54 \log _{10} \mathrm{UFC/g}$, mientras que la prueba de control en el día 17, ya había sobrepasado los 8 log10 UFC/g.

\section{Conclusiones}

El uso de quitosano y extracto de cebolla no influyó en la calidad sensorial del producto, los tratamientos no mostraron grandes diferencias en sus características organolépticas. Sin embargo, el recubrimiento de mayor aceptación sensorial fue T6 elaborado con 3 \% de quitosano y $1 \%$ de extracto de cebolla.

El análisis de bases nitrogenadas volátiles en el tratamiento de mayor aceptación sensorial (T6: quitosano al $3 \%$ y extracto de cebolla al $1 \%$ ) obtuvo valores por debajo de los rangos permisibles según lo estipulado en la normativa legal vigente NTE INEN 182 (30 mg N/100 g) hasta los 21 días en refrigeración: 10.92 mg N/100 g (7 días), 18.48 mg N/100 g (14 días) y $29.12 \mathrm{mg} \mathrm{N} / 100 \mathrm{~g}$ (2l días).

El análisis microbiológico evidenció que hasta el séptimo día de almacenamiento los aerobios mesófilos se mantuvieron ausentes ( $110 \mathrm{UFC/g}$ ), luego de lo cual se observó un incremento de 8 × $102 \mathrm{UFC/g}$ a los 14 días y 1.9 x $103 \mathrm{UFC/g}$ a los 21 días de almacenamiento en refrigeración; dichos valores están dentro de los rangos establecidos en la normativa legal vigente ( 1 x 105 UFC/g). Así mismo, se comprobó la ausencia de Coliformes totales y E. coli durante el tiempo establecido.

\section{Referencias}

Cadena, M. T. O. (2019). Diseño de un recubrimiento activo comestible usando cera de abeja y mezcla de proteína de quinua-quitosano entrecruzada con transglutaminasa y su aplicación en tuna (Opuntia ficusindica) (Tesis de Maestría). Universidad Autónoma de Querétaro, México.

Condori Sánchez, C. (2014). Deterioro y conservación de alimentos. Tesis de grado. Universidad Nacional de San Agustín de Arequipa.

García, H. (2009). Efectos de películas de quitosano sobre la vida de anaquel del queso panela. Tesis de licenciatura. Departamento de Ciencia y Tecnología de Alimentos. Universidad Autónoma Agraria Antonio Narro. Saltillo, Coahuila, México.

Mero Plaza, M. A., y Valencia Cagua, E. J. (2018). Elaboración de un recubrimiento comestible para filetes de tilapia roja (oreochromis sp) a partir de almidón de yuca (manihot esculenta crantz) y aceite esencial 
REVISTA DE LA UNIVERSIDAD DEL ZULIA. $3^{a}$ época. Año $13 \mathrm{~N}^{\circ}$ 36, 2022

Dolores Betún Beltrán et al. /// Efecto de un recubrimiento a base de quitosano y extracto de cebolla ...70-79 DOI: http://dx.doi.org/10.46925//rdluz.36.05

de romero (rosmarinus officinalis) (Bachelor's thesis, Universidad de Guayaquil, Facultad de Ingeniería Química).

Mero, M. y Valencia, E. (2018). Elaboración de un recubrimiento comestible para filetes de tilapia roja (Oreochromis sp) a partir de almidón de yuca (Manihot esculenta crantz) y aceite esencial de romero (Rosmarinus officinalis). Tesis de grado. Universidad de Guayaquil. Guayaquil.

Montaño Cota, E. (2016). Efecto de un extracto etanólico obtenido a partir de la planta de tomate (Solanum lycopersicum) incorporado en un recubrimiento comestible a base de quitosano sobre la frescura, calidad y vida de anaquel del filete de sierra (Scomberomorus sierra) almacenado en hielo. Tesis de grado. Universidad de Sonora. Hermosillo-Perú.

Oliveira, C., Dragonetti Saucero, J. P., y Friss, C. (2001). Deterioro del pescado: Guía didáctica.

Otero Tuárez, V. O. (2019). Desarrollo y caracterización de recubrimientos comestibles antimicrobianos para la conservación de productos derivados de la pesca.

Raeisi, M. (2014). Effect of carboxymethyl cellulose edible coating containing Zataria multiflora essential oil and grape seed extract on chemical attributes of rainbow trout meat. Veterinary Research Forum. 5 (2) 89-93.

Song, Y. (2011). Effect of sodium alginate-based edible coating containing different antioxidants on quality and shelf life of refrigerated bream (Megalobrama amblycephala), Food control. 1 (22) 608-615.

Suarez-Mahecha, H., y Martínez-Bastidas, Y. C. (2020). Capacidad antimicrobiana de bioconservantes utilizados en recubrimientos comestibles en nuggets de cachama blanca (Piaractus brachypomus). Revista Colombiana de Investigaciones Agroindustriales, 7(1), 7-18.

Valenzuela, C. y Arias, J. (2012). Potenciales aplicaciones de películas de quitosano en alimentos de origen animal: una revisión. Avances en Ciencias Veterinarias, 27 (1). 